\title{
Combination of several rare complications of myocardial infarction in a single patient
}

\author{
Eugeny Fishman, Yosef Blaer*, Amos Katz, Chaim Yosefy \\ Cardiology Department, Barzilai Medical Center Campus, Faculty of Health Sciences, Ben-Gurion University of the Negev, Ash- \\ kelon, Israel \\ Email: "blaer@barzi.health.gov.il
}

Received 30 December 2011; revised 27 February 2012; accepted 6 March 2012

\begin{abstract}
There are three major mechanical complications of acute myocardial infarction: rupture of the left ventricular free wall, rupture of the interventricular septum, and development of mitral regurgitation. Each of these complications is associated with extremely high mortality. Reviewing the scientific literature, we found descriptions of sporadic cases of both of those complications combined. We report an unusual case of simultaneous rupture of free wall and interventricular septum.
\end{abstract}

Keywords: Complications; Acute Myocardial Infarction; Aortic Stenosis; Mitral Regurgitation; Transcatheter

\section{CASE REPORT}

The 80-year-old female patient (pt) was brought to the Emergency Department unconscious. Her medical history was remarkable for cerebrovascular accident (CVA) two years ago with residual motor aphasia and left hemiparesis. Her functional capacity was severely limited.

On examination pt was in stupor, with severe dyspnea, hypotensive, and signs suggestive of right ventricular myocardial infarction (MI). On X-ray lung fields were free from pulmonary congestion. ECG showed signs of reperfusion of Acute ST Elevation inferior wall Myocardial Infarction (STEMI).

Bedside echocardiography (echo) revealed severe right and moderate left ventricular dysfunction due to inferopostero-lateral akinesia, mild-moderate aortic regurgitation (AR), and large pericardial effusion with thrombus (Figure 1). An echo finding of right MI, AR, and pericardial effusion raised suspicion of aortic dissection.

Transesophageal two-dimension (2D) and three-dimension (3D) echocardiography displayed ruptured postero-lateral wall proximal to papillary muscle. The rup-

\footnotetext{
${ }^{*}$ Corresponding author.
}

ture was sealed by a huge thrombus that filled the pericardial space and led to collapse of the right ventricle. Incomplete rupture involving the interventricular septum (IVS) was also observed, but no shunting was seen on color Doppler imaging.

Two options of surgical treatment were raised by the cardiac surgeon. The first was open heart surgery with cardio-pulmonary bypass. Euroscore was calculated and in our case was found to approach 90\%. [1] The second strategy was to use biological glue to seal the rupture, with much lower morbidity and mortality [2-4]; however, nature had already done this with a thrombus ("the best biological glue existing”). After discussion, medical treatment was chosen.

Due to lack of response to massive fluid infusion, intravenous Dopamine and Dobutamine were administered. Her condition improved gradually and the patient was easily weaned from mechanical ventilation.

On the $4^{\text {th }}$ day a new $3 / 6$ systolic murmur was heard in $4^{\text {th }}$ interspace at the left sternal border (LSB). Repeat 2D echo demonstrated left to right shunting through the interventricular septum (Figure 2). Complete IVS rupture

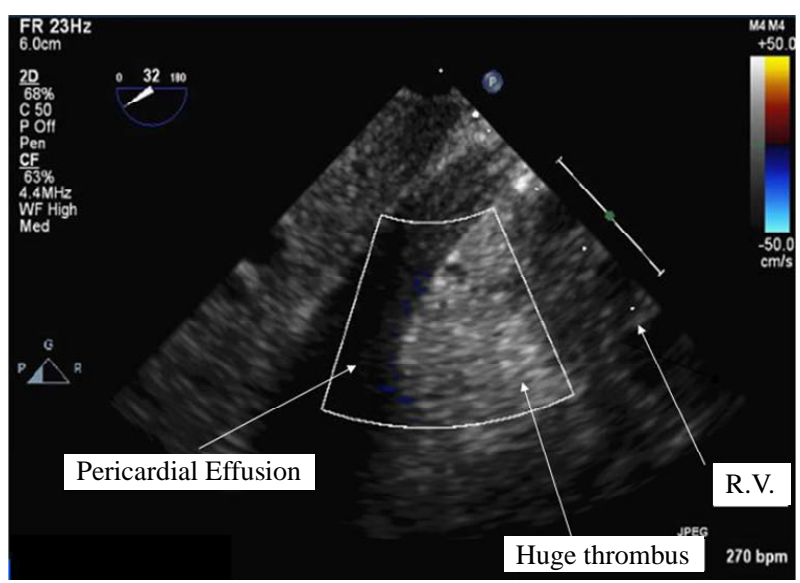

Figure 1. Bedside echocardiography demonstrating severe right (RV) and moderate left ventricular dysfunction due to infero-postero-lateral akinesia, mild-moderate aortic regurgitation (AR), and large pericardial effusion with huge thrombus. 


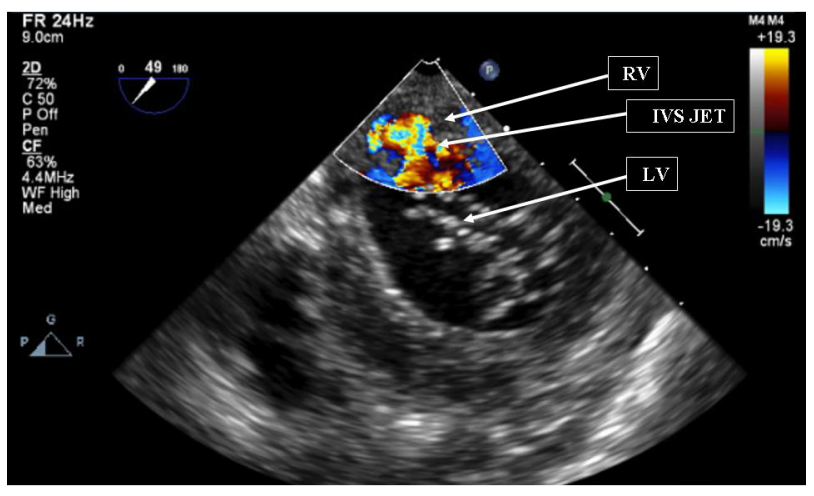

Figure 2. Color Doppler imaging showing incomplete rupture involving the interventricular septum (IVS) with shunt (IVS JET) from left ventricle (LV) to right ventricle (RV).

was diagnosed. Heart surgery was again rejected in favor of a medical approach.

The patient died suddenly the next day.

\section{DISCUSSION}

Reviewing the scientific literature, we found descriptions of sporadic cases of these two complications combined. [5-7] the prevalence of acute ventricular septum rupture (VSR) appears to have declined in the reperfusion era. It is estimated to occur in $1 \%-3 \%$ of patients with STEMI without reperfusion therapy [8], $0.2 \%-0.34 \%$ with fibrinolytic therapy [9], and 3.9\% among patients with cardiogenic shock. [10] VSR is more likely to occur in patients who are older, female, and hypertensive; nonsmokers; with anterior MI location with tachycardia; increased heart rate; and worse Killip class on admission. [9] there is a bimodal peak of VSR appearance-within 24 hours and at 3 - 5 days. Typical clinical manifestations are chest pain, shortness of breath, and hypotension. Physical findings are harsh holosystolic murmur, thrill, S3, accentuated $2^{\text {nd }}$ heart sound, pulmonary edema, RV and LV failure, and cardiogenic shock. [11] echo with color flow imaging is the test of choice for diagnosis of VSR. Surgical closure is the treatment of choice even if the patient's condition is stable, but mortality remains high and has been reported to be between $20 \%$ and 50\%. [9,12-14] Mortality is particularly high in patients with VSR and cardiogenic shock-87\% in the SHOCK Registry. [10] However, surgical mortality is significantly less than for medically treated patients. In GUSTO-I, mortality rates for surgically or medically treated patients were $47 \%$ and $94 \%$, respectively [9].

Rupture of ventricular free wall occurs in $0.8 \%-6.2 \%$ of STE MI patients. [8] there is also a bimodal peak-within 24 hours and after 3 days. [11] There are three distinct types of free wall rupture. Type 1 ruptures occur within the first 24 hours and are full-thickness ruptures (this rupture type increases with thrombolysis); type 2 ruptures occur as a result of erosion of the myocardium at the site of infarction; and type 3 ruptures occur late and are located at the border zone between infarcted and normal myocardium, and occur less frequently in patients treated with thrombolytics. [15] Emergency thoracotomy with surgical repair is the definitive therapy. There are several terms for ruptures that do not traverse all layers of myocardium-slow or incomplete tear leading to a late rupture, or subacute rupture. [16,17]

Frequency of VSR and incomplete free wall rupture combined is unknown, but is undoubtedly very low. In our case, the patient's presentation with cardiogenic shock and timely performance of an echocardiogram allowed for rapid diagnosis of these rare complications. Due to severe comorbidities and advanced age, surgical risk was estimated to be prohibitively high, and the natural history of medically treated heart rupture was observed. The uniqueness of this case is in the simultaneous development of rupture at several heart sites, with the patient surviving free wall rupture and septal rupture. Surprisingly, the patient survived acute free wall rupture by sealing the ventricular wall defect with a thrombus, and despite hemopericardium with impaired right ventricular filling, her hemodynamics normalized, so that inotropic amines and intravenous fluids could be discontinued. Several days later partial interventricular septum rupture progressed to complete, probably due to infarct expansion, but even after VSR with left-to-right shunt, the patient's condition remained stable. It is possible that dissolution of the thrombus sealing the ruptured free wall led to tamponade and sudden death of the patient. Post mortem was not performed.

\section{CONCLUSION}

This case of simultaneous rupture of the free wall and interventricular septum indicates that myocardial rupture is still a lethal complication, no matter the location, or whether there is temporary improvement of hemodynamic status, if no surgical intervention is applicable.

\section{REFERENCES}

[1] Roques, F., Nashef, S.A., Michel, P., Gauducheau, E., De Vincentiis, C., Baudet, E., Cortina, J., David, M., Faichney, A., Gabrielle, F., Gams, E., Harjula, A., Jones, M.T., Pintor, P.P., Salamon, R. and Thulin, L. (1999) European system for cardiac operative risk evaluation (EuroSCORE). European Journal of Cardiothoracic Surgery, 6, 9-13.

[2] Lachapelle, K., De Varennes, B., Ergina, P.L. and Cecere, R. (2002) Sutureless patch technique for postinfarction left ventricular rupture. Annals of Thoracis Surgery, 74, 96-101. doi:10.1016/S0003-4975(02)03581-6 
[3] Iemura, J., Oku, H., Otaki, M., Kitayama, H., Inoue, T. and Kaneda, T. (2001) Surgical strategy for left ventricular free wall rupture after acute myocardial infarction. Annals of Thoracic Surgery, 71, 201-204. doi:10.1016/S0003-4975(00)02211-6

[4] Aris, A. (2005) Surgical repair of left ventricular free wall rupture. Multimedia Manual of Cardio-Thoracic Surgery, 2005, 167. doi:10.1510/MMCTS.2004.000653

[5] Pohjola-Sintonen, S., Muller, J.E., Stone, P.H., Willich, S.N., Antman, E.M., Davis, V.G., Parker, C.B. and Braunwald, E. (1989) Ventricular septal and free wall rupture complicating acute myocardial infarction: Experience in the multicenter investigation of limitation of infarct size. American Heart Journal, 117, 809-818. doi:10.1016/0002-8703(89)90617-0

[6] Svedjeholm, R., Håkanson, E., Lindström, M. and Hjort, P. (2003) Post-infarct left ventricular free wall rupture and ventricular septal defect managed by pericardial aspiration during transport to referral hospital. Interactive Cardiovascular and Thoracic Surgery, 2, 193-195. doi:10.1016/S1569-9293(03)00038-0

[7] Kalkan, M.E., Arsian, S., Sevimli, S. and Gurlertop, H.Y. (2008) Ventricular double rupture case of long-term survival without surgical repair. European Journal of Echocardiography, 231, 1-3.

[8] Birnbaum, Y., Fishbein, M.C., Blanche, C. and Siegel, R.J. (2002) Ventricular septal rupture after acute myocardial infarction. New England Journal of Medicine, 347, 1426-1432. doi:10.1056/NEJMra020228

[9] Crenshaw, B.S., Granger, C.B., Birnbaum, Y., Pieper, K.S., Morris, D.C., Kleiman, N.S., Vahanian, A., Califf, R.M. and Topol, E.J. (2000) GUSTO-I (Global Utilization of Streptokinase and TPA for Occluded Coronary Arteries) Trial investigators. Risk factors, angiographic patterns, and outcomes in patients with ventricular septal defect complicating acute myocardial infarction. Circulation, 101, 27-32.

[10] Hochman, J.S., Buller, C.E., Sleeper, L.A., Boland, J., Dzavik, V., Sanborn, T.A., Godfrey, E., White, H.D., Lim, J. and LeJemtel, T. (2000) Cardiogenic shock complicating acute myocardial infarction: Etiologies, management and outcome: A report from the SHOCK Trial Registry. Should we emergently revascularize Occluded Coronaries for cardiogenic shock? Journal of the Ameri- can College of Cardiology, 36, 1063-1070. doi:10.1016/S0735-1097(00)00879-2

[11] ACC/AHA Guidelines for the Management of Patients with ST-Elevation Myocardial Infarction (2004) A Report of the American College of Cardiology/American Heart Association Task Force on practice guidelines (Writing committee to revise the 1999 guidelines for the management of patients with acute myocardial infarction). Circulation, 110, 588-636. doi:10.1161/01.CIR.0000134791.68010.FA

[12] Prêtre, R., Ye, Q., Grünenfelder, J., Lachat, M., Vogt, P.R. and Turina, M.I. (1999) Operative results of "repair" of ventricular septal rupture after acute myocardial infraction. American Journal of Cardiology, 84, 785-788. doi:10.1016/S0002-9149(99)00438-5

[13] Lemery, R., Smith, H.C., Giuliani, E.R. and Gersh, B.J. (1992) Prognosis in rupture of the ventricular septum after acute myocardial infarctionand role of early surgical intervention. American Journal of Cardiology, 70, 147151. doi:10.1016/0002-9149(92)91266-7

[14] Skillington, P.D., Davies, R.H., Luff, A.J., Williams, J.D., Dawkins, K.D., Conway, N., Lamb, R.K., Shore, D.F., Monro, J.L. and Ross, J.K. (1990) Surgical treatment for infarct-related ventricular septal defects: Improved early results combined with analysis of late functional status. Journal of Thoracic and Cardiovascular Surgery, 99, 798-808.

[15] Bartunek, J., Vanderheyden, M. and De Bruyne, B. (1995) Dynamic left ventricle outflow tract obstruction after anterior myocardial infarction: A potential mechanism of myocardial rupture. European Heart Journal, 16, 14391442.

[16] Helmy, T.A., Nicholson, W.J., Lick, S. and Uretsky, B.F. (2005) Contained myocardial rupture: A variant linking complete and incomplete rupture. Heart, 91, e13. doi:10.1136/hrt.2004.048082

[17] Pollak, H., Diez, W., Spiel, R., Enenkel, W. and Mlczoch, J. (1993) Early diagnosis of subacute free wall rupture complicating acute myocardial infarction. European Heart Journal, 14, 640-648. $\underline{\text { doi:10.1093/eurheartj/14.5.640 }}$ 